\title{
Salinity as a driver of aquatic invertebrate colonisation behaviour and distribution in the wheatbelt of Western Australia
}

\author{
Scott Carver · Andrew Storey · Helen Spafford • \\ Jessica Lynas $\cdot$ Lisa Chandler $\cdot$ Philip Weinstein
}

Received: 15 January 2008/Revised: 27 April 2008/Accepted: 14 July 2008/Published online: 1 August 2008

(C) Springer Science+Business Media B.V. 2008

\begin{abstract}
To understand how environmental change will modify community assembly and the distribution of organisms it is valuable to understand mechanisms that drive the occurrence of organisms across the landscape. Salinisation of agricultural land in southwest Western Australia, as a result of land clearing, is a widespread environmental change, which threatens numerous taxa, but provides an opportunity to elucidate such mechanisms. Although salinisation affects terrestrial fauna and flora, the greatest impacts are seen in wetlands and waterways. Many aquatic insect taxa colonise ephemeral water bodies directly as adults or by oviposition. Few empirical studies, however, evaluate the influence of abiotic factors, such as water body salinity, on the colonisation behaviour of aquatic fauna. We conducted a manipulative experiment using mesocosms to test whether colonising insect fauna select aquatic habitats based upon salinity. We found
\end{abstract}

Handling editor: K. Martens

S. Carver $(\bowtie) \cdot$ A. Storey $\cdot$ H. Spafford .

J. Lynas · L. Chandler

School of Animal Biology (M085), University of Western

Australia, 35 Stirling Highway, Crawley, WA 6009,

Australia

e-mail: scott.carver@grs.uwa.edu.au

S. Carver · P. Weinstein

School of Population Health (M431), University

of Western Australia, 35 Stirling Highway, Crawley,

WA 6009, Australia that halosensitive fauna selected less saline mesocosms for oviposition and colonisation, demonstrating that behaviour can influence the distribution of aquatic organisms. Additionally, we utilised field surveys of insects from ephemeral water bodies across a broad region of southwest Western Australia to determine if mesocosm results reflected field observation. The abundance of the same insect taxa and taxonomic groups in the field were highly variable and, with the exceptions of Culex australicus Dobrotworksy and Drummond and Anopheles annulipes Giles (Diptera: Culicidae), did not show similar patterns of distribution to those observed in the mesocosm experiment. Both mesocosm and field assemblages exhibited similar and significant trajectories associated with the salinity gradient, even though there were differences in assemblage structure between the two. Our findings give empirical support to the importance of behaviour in the spatial distribution and assembly of some aquatic insects.

Keywords Dryland salinity - Oviposition · Colonisation - Behaviour - Community assembly . Temporary pools

\section{Introduction}

Understanding mechanisms that generate the spatial distributions of organisms in modified landscapes is one of the major goals of ecology (Crain et al., 2004). 
Anthropogenic (secondary) salinisation of arid and Mediterranean lands occurs globally and influences the distribution of aquatic assemblages across the landscape (Roberts \& Irving-Bell, 1997; Halse et al., 2003; Hart \& Lovvorn, 2005; Pinder et al., 2005; Piscart et al., 2005b). General consensus exists that increasing river and wetland salinity has potential to cause local extinctions, alterations in ecosystem function and extensive environmental damage (Halse et al., 2003; Kefford et al., 2003; Jardine et al., 2007). Halse et al. (2003) predicted that approximately one-third of aquatic invertebrate diversity in the inland southwest of Western Australia (WA) will disappear with the expansion of secondary salinisation, and Pinder et al. (2005) suggested that up to 100 species that are largely restricted to the inland southwest are at risk of extinction. However, biotic factors, such as behaviour, are also important drivers of organism distribution, but considered less frequently (Stoks \& McPeek, 2003; Blaustein et al., 2004). James et al. (2003) and Neilsen et al. (2003) suggested that behavioural avoidance of saline water bodies may assist the persistence of mobile halosensitive aquatic fauna, but empirical support is needed.

Behavioural selection of habitat is a determinant of animal distribution in terrestrial (Singleton, 1989; Terpstra \& Wilson, 1989) and aquatic systems (Mokany \& Shine, 2003; Blaustein et al., 2004; Silberbush et al., 2005). Numerous studies have documented biotic interactions, such as predation and competition, influencing oviposition decisions by mosquitoes (Diptera: Culicidae) (Stav et al. 1999; Juliano \& Gravel, 2002; Mokany \& Shine, 2003; Blaustein et al., 2004; Hagman \& Shine, 2006), and most likely colonisation by other insects with aquatic life phases. Surprisingly, the influence of abiotic conditions, such as water chemistry, is rarely documented with reference to colonisation behaviour (whether by direct colonisation as an adult or oviposition) (Trimble \& Wellington, 1979; Bailey et al., 1981; Pappas \& Pappas, 1983; Roberts, 1996; Silberbush et al., 2005).

Colonisation of aquatic habitats by insects in secondary salinised landscapes is useful to evaluate how an abiotic gradient influences selection of aquatic habitat and organism distribution. Detection of salinity by colonisers has consequences for survival and fitness and is likely to influence colonisation behaviour, population and assemblage structure. For example, in saline habitats: survival of Cloeon sp. and Centroptilum sp. (Ephemeroptera: Baetidae) decreases (Hassell et al., 2006); developmental rates and survival are reduced for Chironomus sp. (Diptera: Chironomidae) (Hassell et al., 2006), Aedes taeniorhynchus Wiedemann and Aedes aegypti L. (Diptera: Culicidae) (Clark et al., 2004); and survival is reduced for Culex australicus Dobrotworsky and Drummond and Aedes camptorhynchus Thomson (Diptera: Culicidae) (van Schie, unpublished data). This article examines the influence of salinity on colonisation of water bodies by insect taxa using a manipulative mesocosm experiment in the field (Fig. 1). A field survey of ephemeral water bodies, across a broad region of southwest WA (Fig. 1), and encompassing saline and non-saline land, is used to determine if mesocosm results reflect field observations.

The inland southwest of WA (the Wheatbelt) is substantially affected by secondary salinisation, as a

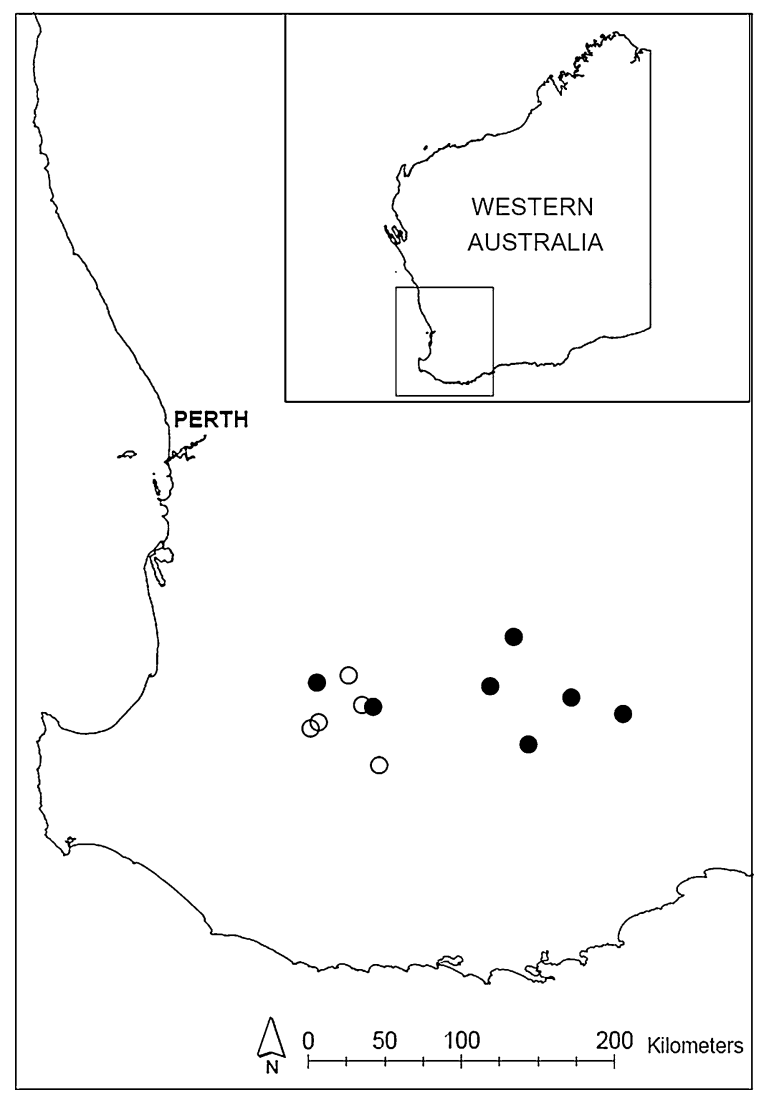

Fig. 1 Sites used for the mesocosm experiment (open circles) and field surveys (open and closed circles) of aquatic invertebrates in the Wheatbelt of southwest WA 
consequence of land clearing and rising groundwater tables bringing stored salt to the surface (McKenzie et al., 2003). Currently more than one million hectares are affected and salinisation is expected to expand twoto fourfold by 2050 (George et al., 2006; Jardine et al., 2007). Ephemeral water bodies are characteristic of the Wheatbelt, where they show a range of salinities, especially in areas affected by secondary salinisation, making them ideal to investigate how salinity affects the colonisation and oviposition behaviour of insects. Numerous studies have investigated how salinity influences the distribution of aquatic organisms by examining patterns in species occurrence (Halse, 1981; Bunn \& Davies, 1992; Kay et al., 2001; Williams, 2003; Halse et al., 2004; Marshall \& Bailey, 2004; Pinder et al., 2004; Piscart et al., 2005a) and salt sensitivity (Roberts, 1996; Blasius \& Merritt, 2002; Kefford et al. 2003; Jeffery et al. 2005; Hassell et al., 2006; Zalizniak et al., 2006). Studies have found a range of invertebrate fauna, such as the disease vector Ae. camptorhynchus, to be prevalent in saline areas (Pinder et al., 2005; Jardine et al., 2007; Lindsay et al., 2007). However, little attention has been given to the significance of colonisation behaviour in distribution (but see, Silberbush et al., 2005). Laboratory studies demonstrate salinity influences oviposition preferences of mosquitoes (Trimble \& Wellington, 1979; Bailey et al., 1981; Pappas \& Pappas, 1983; Roberts, 1996), but laboratory results do not always reflect field distributions. For example, Sinha (1976) found Culex quinquefasciatus Say (Diptera: Culicidae) has ovipositional preferences for freshwater, but observed abundant larvae at salinities $\leq 7.5 \mathrm{gl}^{-1}$ total dissolved solids (TDS) in the field. Inconsistencies between laboratory and field results undoubtedly result from additional biotic and abiotic inputs (such as predation, competition, microhabitat structure, habitat availability and stochastic encounters with water bodies). As such, patterns in assemblages of colonisers across a salinity gradient may be more holistically informative of how salinity influences colonisation behaviour, in the presence of other variables, than individual taxa alone (Halse et al., 2004; Pinder et al., 2005). Additionally, analyses of assemblages enable the relative contributions of fresh water and halophilic fauna to be readily quantified.

This study examines the hypothesis that salinity influences colonisation behaviour and the structure of insect assemblages in the field. This unifying hypothesis is evaluated through two supporting hypotheses: (1) salinity in mesocosms will affect colonisation by individual taxa and assemblages of insects and (2) responses of fauna to salinity in mesocosms will reflect responses of fauna observed in field surveys. These supporting hypotheses link the role of salinity, as an abiotic gradient, on colonisation behaviour and the general importance of colonisation behaviour as a determinant of field assemblage structure. The mesocosm experiment is conducted in areas of the Wheatbelt with minimal secondary salinisation (water bodies $0-3 \mathrm{gl}^{-1}$ TDS), but where water tables are rising and future salinity is anticipated (Fig. 1). As such, it was expected that most aquatic fauna of mesocosms would be freshwater taxa. Dispersal of aquatic insects in the wheatbelt is widespread, but locally heterogeneous, due to variation in habitat (Kay et al., 2001; Pinder et al., 2005). It is anticipated that insects colonising mesocosms vary in space and time.

\section{Materials and methods}

Study area

This study was undertaken in the Great Southern meteorological district of the WA Wheatbelt (Fig. 1). The study area has a Mediterranean climate with hot dry summers and mild wet winters. Annual rainfall declines from approximately $600 \mathrm{~mm}$ at the western boundary of our study area to $350 \mathrm{~mm}$ in the east (Australian Bureau of Meteorology). Approximately 80-90\% of the region has been cleared for agriculture (Halse et al., 2004). Sites were located in remnant native vegetation and were chosen to correspond with locations previously used by the WA Department of Environment and Conservation to assess the impacts of secondary salinisation (Keighery et al., 2004).

\section{Mesocosm experiment}

Mesocosms were constructed at five sites in April and May 2006 (autumn) (Fig. 1). At this time of year there were few water bodies, because negligible rainfall occurs during summer and autumn, and the occurrence of insect families in mesocosms would be the result of opportunistic colonisation by highly mobile species (Kay et al., 2001). Each mesocosm consisted of a 
circular hole dug into the soil $(25 \mathrm{~cm}$ diameter $\times 10 \mathrm{~cm}$ depth), lined with black polythene and filled with approximately 51 of aged tap water. Each mesocosm was seeded with $10 \mathrm{~g}$ of nutrients (guinea pig and rabbit pellets, Specialty Feeds Western Australia), and 10 tillers of an emergent rush Juncus sp. were added to create habitat complexity. At each site, five salinity levels were established $(0,5,10,15$ and $20 \mathrm{gl}^{-1}$ TDS (uniodised table salt, Asia/Pacific Wholesalers Pty. Ltd.)), with three replicates of each level, giving a total of 75 individual experimental units. At each site mesocosms were arranged randomly in a $3 \times 5$ grid with each mesocosm separated by $1 \mathrm{~m}$. On a weekly basis, for 6 weeks, each mesocosm was sampled for insects using a $10-\mathrm{cm}$ diameter aquatic net (mesh size $250 \mu \mathrm{m}$ ), giving a total of 450 individual samples. Each sample consisted of two consecutive net sweeps through the mesocosm with each net sweeping down through the water column and up the wall of the mesocosm (approx 1.61 (32\%) of the mesocosm volume sampled in each sweep). All samples were preserved in $70 \%$ ethanol for laboratory analysis. In the laboratory, all insects were removed and identified under a microscope: Culicidae were identified to species and Coleoptera to genus. All other Diptera were uncommon and identified to family, except Chironomidae. Chironomidae sampled from the mesocosms were identified to be a single species, Chironomus alternans Walker (Diptera: Chironomidae), but comprised multiple unidentified species in the field. The richness of taxonomic groups, abundance of insects and abundance of each taxonomic group was recorded. Additionally, the abundance of insects classified by their suspected means of colonisation was recorded: ovipositing insects (dipteran larvae) and direct colonisers (Coleoptera, because only adult stages were recorded in mesocosms).

On each sampling occasion, mesocosm salinity was recorded and, where necessary, regulated by either the addition of water or salt to negate the effects of evapoconcentration or rainfall, respectively. During April there were occasional rainfall events that caused dilution to the mesocosms and as a result it took three sampling weeks to establish and stabilise the five distinct salinity levels used in this field experiment. During May 2006, local weather patterns stabilised and distinct differences in the salinity levels were maintained thereafter (repeated measures GLM $\left.F_{4,}, 70=610.740, \quad P<0.001\right)$.
Consequently the mesocosm data from May have been used for analysis in this paper. During May 2006 the relative humidity was reasonably high (average range 50-80\%) and rainfall events were rare (month average, $<1 \mathrm{~mm}$ day $^{-1}$ ). Evapoconcentration and dilution of mesocosms were negligible throughout this time. Mesocosm $\mathrm{pH}$ was also measured and remained within a relatively narrow range throughout the experiment (6.8-7.2). There was a significant negative effect of salinity on $\mathrm{pH}$ (repeated measures GLM $F_{4,70}=5.413, P<0.001$ ), attributable to reductions in algal proliferation at higher salinities (Carver, personal observation).

\section{Field surveys}

Abundance and diversity of aquatic insects from naturally occurring water bodies in the field were collected as part of a larger study to examine the effects of secondary salinisation on invertebrate assemblages (Carver, manuscript in prep). A portion of the data (the same taxonomic groups occurring in the mesocosms) is used herein to provide a comparison to the mesocosm experiment. From September to November 2005 (spring) and February to May 2006 (late summer and autumn) surveys of aquatic invertebrates occurring in small $\left(0.2 \times 10^{-5}-0.97\right.$ ha) rain-fed ephemeral water bodies were conducted fortnightly across 12 sites (Fig. 1). These seasons were chosen to maximise the number of water bodies and the range of salinities observed in the field. Winter was not sampled because higher rainfall results in fewer saline water bodies, and in summer there are few water bodies due to low rainfall, high temperatures and evaporation.

At each site, a one-hectare square quadrat was established in a low-lying area. In each quadrat the dimensions and shape of all water bodies were measured and used to calculate the surface area for each water body. Aquatic invertebrates were sampled from each water body, resulting in a total of 180 samples. Samples consisted of sweeping a standard D-frame 500-mm diameter FBA pond net $(250-\mu \mathrm{m}$ mesh size: Australian Entomological Supplies Pty. Ltd.). Every effort was made to sample all microhabitats within a water body. Up to $10 \mathrm{~m}^{2}$ surface area was swept per water body. In water bodies with a surface area less than $10 \mathrm{~m}^{2}$ a smaller area was sampled. Neither taxonomic richness nor density was related to sampling area (linear regressions $r^{2}=0.06$, 
$F_{1,178}=1.057, P=0.305$ and $r^{2}=0.007, F_{1,178}=$ $1.238, P=0.267$, respectively). The area sampled from each water body was recorded. Salinity of every water body within each site was measured on each sampling occasion. All samples were preserved in $70 \%$ ethanol and returned to the laboratory, where all insects were removed and identified (to the same taxonomic levels as in the mesocosm) under a microscope. Large samples were homogenised and then split into half or quarters for sub-sampling. All insect data were standardised to number of individuals per $\mathrm{m}^{2}$ of water body surface area (number of insects/ sampling area).

To allow comparison between the results from the salinity levels $\left(0,5,10,15\right.$ and $20 \mathrm{gl}^{-1}$ TDS) used in the mesocosm experiment, with results from the field samples, the samples taken from the field were divided into comparable salinity categories (0-5, 5-10, 10-15, 15-20 and 20+ $\mathrm{gl}^{-1}$ TDS).

\section{Analyses}

To test the effects of time, site and salinity on the richness of taxa and abundance of taxonomic groups sampled from the mesocosms, a three-factor General Estimating Equation (GEE, in SPSS 15.0, SPSS Inc. Chicago, US), with time as a repeated measure, was used. GEE was used because taxa were heterogeneously distributed amongst mesocosms and between sites, and data could not reliably be normalised by transformation. An Omnibus test was used to specify the optimal distribution and transformation of the taxa (Poisson or negative binomial probability distribution and identity or log-link function, respectively) for the analysis. GEE were performed on an independent correlation matrix. The main effects (time, site and salinity) were examined, and interactions were added to the analysis, using a forward selection process, where they gave a more parsimonious model, based on the corrected quasi-likelihood information criterion.

To examine the effect of salinity on the richness and abundance of the taxa collected in the field samples, a Generalized Linear Model (GZLM, in SPSS 15.0, SPSS Inc. Chicago, US) was used. The optimal distribution and transformation of taxa data were specified using an Omnibus test, as described for GEE. Tukey's post hoc analyses were employed to compare levels within treatments in the GEE and GZLM analyses.
To determine if salinity, site and time had effects on the assemblages of insects occurring in mesocosms, a PERMANOVA (permutation based MANOVA) was used (Anderson, 2005). The effect of salinity on field assemblages was examined using a NPMANOVA (non-parametric permutation-based MANOVA) because this analysis allowed comparison of uneven sample sizes (Anderson, 2004). In both cases the assemblage data were square-root transformed to down-weight the dominance of highly abundant species on the analyses, and Bray-Curtis dissimilarity matrices were calculated. Post hoc analyses pairwise comparisons were used to determine significance between the levels. Non-Metric Multidimensional Scaling (NMDS, PRIMER v6, PRIMER-E Ltd: Plymouth, UK), based on square-root transformed data and Bray-Curtis dissimilarity matrices, was used to ordinate the data for visualisation.

Multivariate trends in assemblage changes, between salinity levels, were calculated and compared between the mesocosm and field data. To calculate multivariate trends, the centroid for each salinity level was calculated from the transformed dissimilarity matrix, and the distance between centroids for each salinity level calculated using a Principle Coordinate analysis (PRIMER v6, PRIMER-E Ltd: Plymouth, UK), for mesocosm and field assemblages individually. To compare mesocosm and field multivariate trends, the centroid distance of the lowest salinity level to the centroid of each increasing salinity level, in the mesocosms (i.e. 0 and 5, 0 and 10,0 and 15 , and 0 and $20 \mathrm{gl}^{-1}$ TDS), was plotted against the centriod distances from 0 to $5 \mathrm{gl}^{-1}$ TDS to the centroid of each increasing salinity level, for field assemblages. Multivariate trends were correlated using a Pearson correlation (using SPSS 15.0, SPSS Inc. Chicago, US).

\section{Results}

Insects from two orders, Diptera and Coleoptera, colonised the mesocosms, with the former proportionally more abundant $(87.9 \%)$ than the latter (12.1\%). In field samples, Diptera comprised $99.5 \%$ and Coleoptera $0.5 \%$ of total abundance. All Coleoptera sampled in mesocosms were adults and, in the absence of maturing larvae, presumably actively flew in to colonise, whereas Diptera were larval, and thus 
colonised via oviposition. Taxonomic groups were variable in their occurrence in mesocosm and field water bodies, resulting in low average richness per water body (Fig. 2). There was temporal heterogeneity in the abundance of ovipositing insects in the mesocosms (Table 2). Spatial heterogeneity was also observed for total abundance, taxa richness and the abundance of ovipositing and colonising insects (Table 2).

Influence of salinity on abundance, taxonomic richness, colonising and ovipositing insects

Total insect abundance, taxa richness and the abundance of ovipositing and colonising insects were negatively related to increasing salinity, in the mesocosms (Fig. 2a, b and Tables 1, 2). The abundance of ovipositing insects, and consequently overall abundance, declined in response to salinity levels greater than $0 \mathrm{gl}^{-1}$ TDS (Fig. 2b, Table 1), whereas taxa richness and the abundance of colonisers declined more steadily (Fig. 2a, Table 1). The influence of salinity varied between sites for total abundance, and abundance of ovipositing and colonising insects (see site*salinity interaction, Table 2). Coloniser abundance exhibited strong temporal and spatial variability (see time*site interaction, Table 2 ).

In the field samples, total abundance and densities of ovipositing insects declined at the highest salinity level (Fig. 2b, Table 1). Colonisers occurred at higher densities at salinities exceeding $10 \mathrm{gl}^{-1}$ TDS (Table 2). Overall, the results from the field differed from those observed in the mesocosms (Tables 1,2), possibly reflecting a wider variety of species occurring within taxonomic groups in the field.
Influence of salinity insect taxa

Insects that colonised the mesocosms were predominantly Culex australicus, Anopheles annulipes Giles (Diptera: Culicidae), C. alternans and Paracymus sp. (Coleoptera: Hydrophilidae) (Table 1). Numerous other taxa colonised the mesocosms, but were infrequent in occurrence (Table 1). With the exceptions of Cx. australicus and Necterosoma sp., the abundance of insect taxa did not exhibit temporal variability (Table 2). As expected, heterogeneities existed in the abundance of taxa between sites (Table 2). Site was significant for 6 of the 15 taxonomic groups recorded, and there was a site and time interaction for Paracymus sp. (Table 2).

Salinity influenced the abundance of 4 of the 15 taxonomic groups in the mesocosms (Tables 1, 2). Culex australicus, An. annulipes, C. alternans and Paracymus sp. all became less abundant or absent with increasing salinity level (Table 1). Culex australicus was most abundant at $0 \mathrm{gl}^{-1}$ TDS and least abundant at salinities $>5 \mathrm{gl}^{-1}$ TDS (Table 1). Additionally, rafts of $C x$. australicus eggs were observed less frequently at salinity levels greater than $5 \mathrm{gl}^{-1}$ TDS (although the abundance of egg rafts was not formally recorded). Anopheles annulipes was less abundant, but exhibited a similar if not more sensitive relationship with salinity than $C x$. australicus (Table 1). The abundance of $C$. alternans declined steadily as salinity increased (Table 1). Paracymus sp. became less abundant after $10 \mathrm{gl}^{-1}$ TDS. There was a significant site and salinity interaction effect for Cx. australicus and Paracymus sp., due to heterogeneity in the occurrence of these taxa between sites (Table 2).
Fig. 2 The average richness of taxa (a) and average abundance $( \pm 1 \mathrm{SE})$ (b) of colonising insects across salinity levels $\left(\mathrm{gl}^{-1}\right.$ TDS) for mesocosm (lines) and field (bars) samples, respectively. Mesocosm levels $\left(0,5,10,15,20 \mathrm{gl}^{-1}\right.$ TDS) on the $x$-axis are represented by the first number of each field salinity level
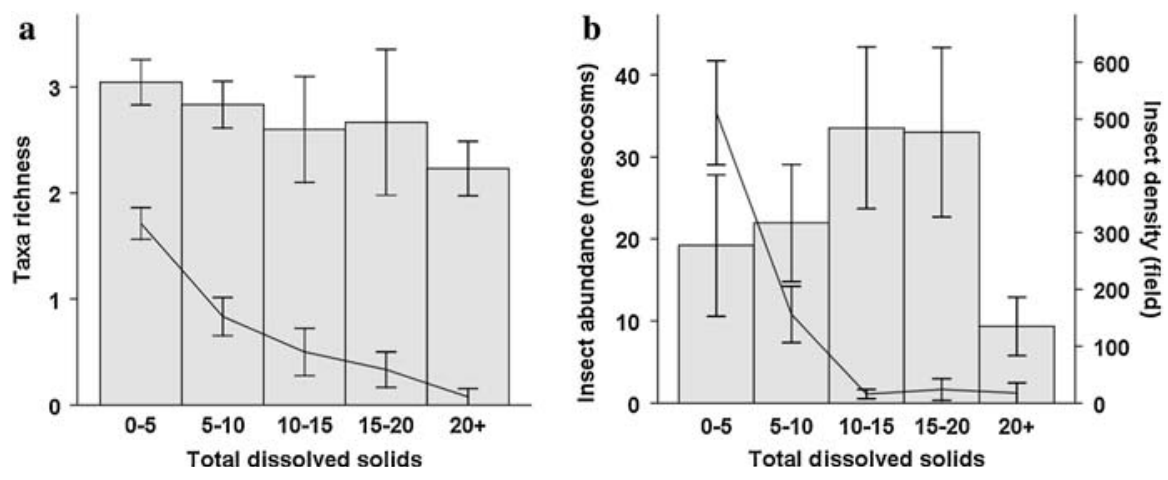


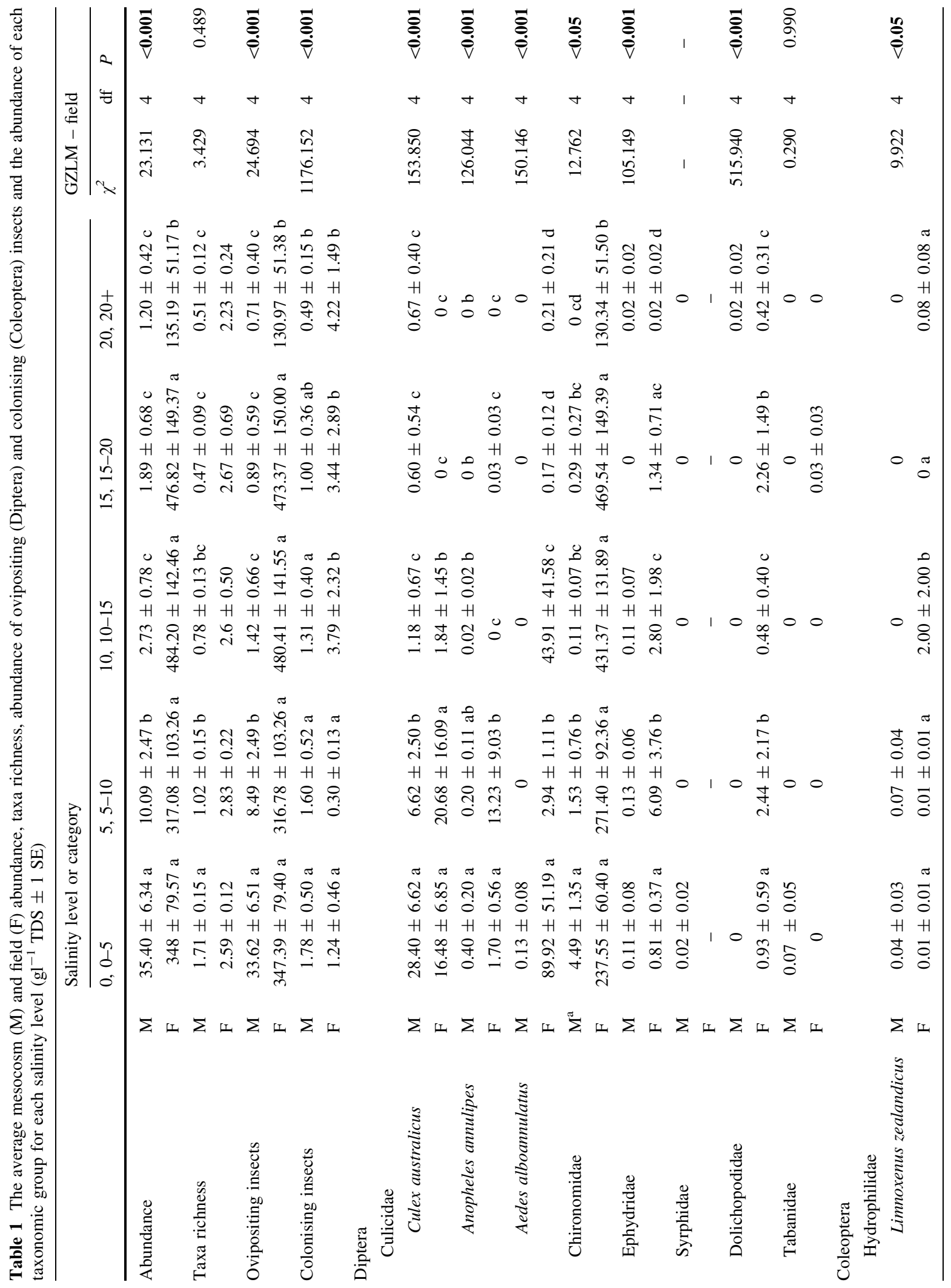




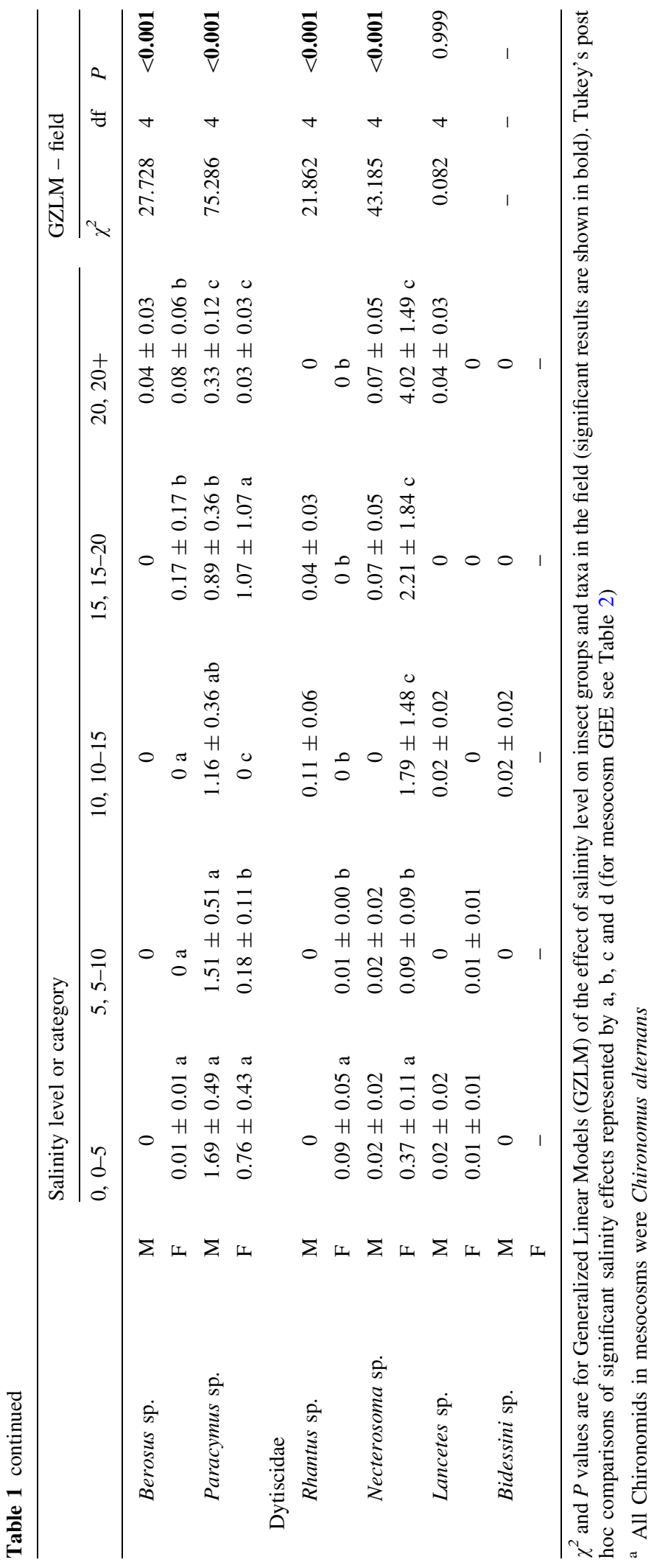




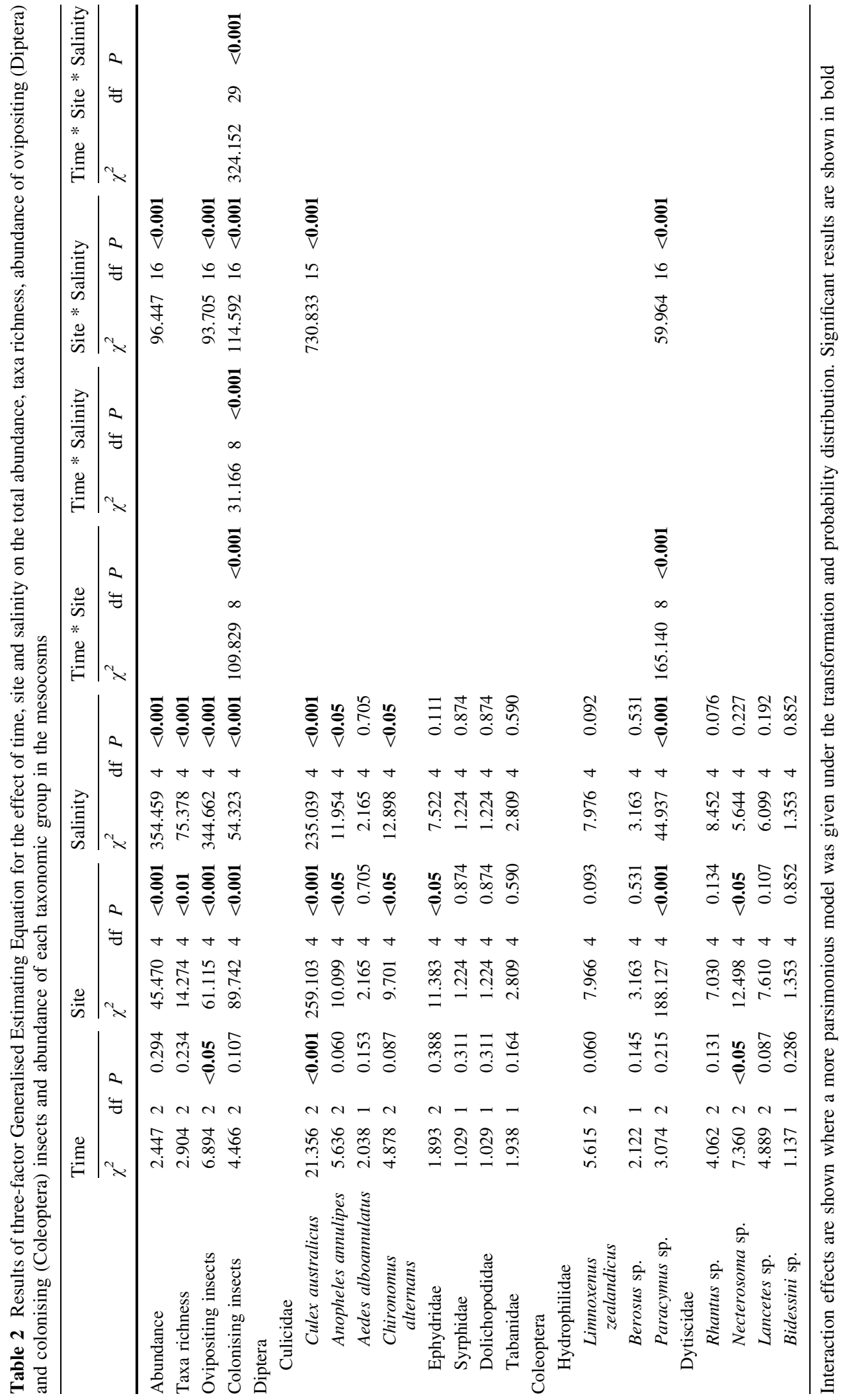


With the exceptions of Ephydridae, Dolichopodidae and Necterosoma sp., taxa that were sampled infrequently in the mesocosms were also sampled infrequently in the field samples (Table 1). The density of numerous taxonomic groups was significantly related to salinity (Table 1). Culex australicus densities declined beyond $10 \mathrm{gl}^{-1}$ TDS (Table 1). Anopheles annulipes and Ephydridae densities were greatest at 5-10 $\mathrm{gl}^{-1}$ TDS and were reduced thereafter (Table 1). The density of Aedes alboannulatus Macquart (Diptera: Culicidae) was heterogeneous between 0 and $15 \mathrm{gl}^{-1}$ TDS, but remained low as salinity exceeded $15 \mathrm{gl}^{-1}$ TDS (Table 1). Densities of Chironomidae were lower at the highest salinity level (Table 1). Necterosoma sp. occurred at greater densities at salinities exceeding $10 \mathrm{gl}^{-1}$ TDS (Table 1). The remaining taxonomic groups were either seldom encountered or had heterogeneous densities between salinity levels (Table 1).

It was difficult to determine clear cases where the same taxonomic group was affected by salinity in both mesocosms and field samples. In the mesocosms, the abundance of Cx. australicus and An. annulipes declined significantly as salinity increased and this pattern was similar in the field, although it is noted that An. annulipes densities were lower at $0-5 \mathrm{gl}^{-1}$ TDS than $5-10 \mathrm{gl}^{-1}$ TDS in the field (Table 1). Overall, the effect of salinity level on individual taxonomic groups in the field differed from those observed in the mesocosms (Tables 1, 2), potentially due to a lack of species level identification of non-culicid fauna.

Influence of salinity on insect assemblages

Analysis of assemblages in mesocosms revealed that assemblage structure changed significantly as salinity increased (Table 3, Fig. 3a). Similar to univariate results of abundance and richness (Table 1), the overall pattern of assemblage composition demonstrated a clear and consistent relationship to the salinity gradient (Fig. 3a). Assemblage structure was also spatially heterogeneous and there were interactions between site and time, and site and salinity (Table 3). Analysis of field data revealed that assemblage structure also changed in relation to the salinity gradient (NPMANOVA $F_{4,175}=2.261$, $P<0.001$, Fig. 3b). Similar trajectories of assemblages across salinity levels were observed between
Table 3 PERMANOVA of the effect of time, site, salinity and interactions on the colonising assemblage of insects in the mesocosms

\begin{tabular}{lrrr}
\hline & \multicolumn{3}{c}{ PERMANOVA } \\
\cline { 2 - 4 } & df & \multicolumn{1}{c}{$F$} & \multicolumn{1}{c}{$P$} \\
\hline Time & 2 & 0.312 & 0.902 \\
Site & 4 & 10.752 & $<\mathbf{0 . 0 0 1}$ \\
Salinity & 4 & 5.038 & $<\mathbf{0 . 0 0 1}$ \\
Time * Site & 8 & 4.8 & $<\mathbf{0 . 0 0 1}$ \\
Time * Salinity & 8 & 1.102 & 0.348 \\
Site * Salinity & 16 & 2.317 & $<\mathbf{0 . 0 0 1}$ \\
Time * Site * Salinity & 32 & 1.136 & 0.189 \\
Error df & 150 & & \\
\hline
\end{tabular}

Significant results are shown in bold

the field and mesocosms (Fig. 3). However, it should be noted that insect assemblages from field surveys were generally of a different composition to those observed in mesocosms.

As salinity level increased in the mesocosms, the centroid distances to the centroid at the lowest salinity level $\left(0 \mathrm{gl}^{-1}\right.$ TDS $)$ increased (Fig. 4). The centroid distances for 10,15 and $20 \mathrm{gl}^{-1}$ TDS were similar (Fig. 4), suggesting assemblages at these salinities were more uniform. Similar to the mesocosms, centroid distances to the lowest salinity level $\left(0-5 \mathrm{gl}^{-1}\right.$ TDS) in the field increased for each increasing salinity level (Fig. 4). Centroid distances for 15-20 and 20+ $\mathrm{gl}^{-1}$ TDS in the field were similar (Fig. 4), again suggesting assemblages at these salinities were more uniform. There was a similar trend between mesocosm and field centroid distances (Pearson correlation $r=0.945, P=0.055$ ), suggesting a similar trajectory in multivariate assemblage response to increasing salinity.

\section{Discussion}

The anthropogenic salinisation of land in southwest WA leads to an abiotic gradient that has a substantial influence upon aquatic organisms and potentially to biodiversity as a whole (Halse et al. 2003, 2004). Yet, adaptive behaviour, such as the avoidance of saline water bodies, may assist the persistence of aquatic invertebrates that are halosensitive and influence 


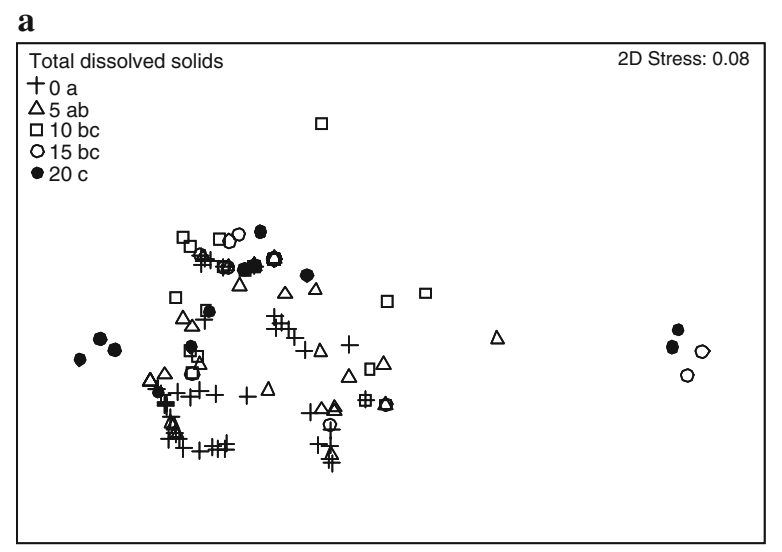

b

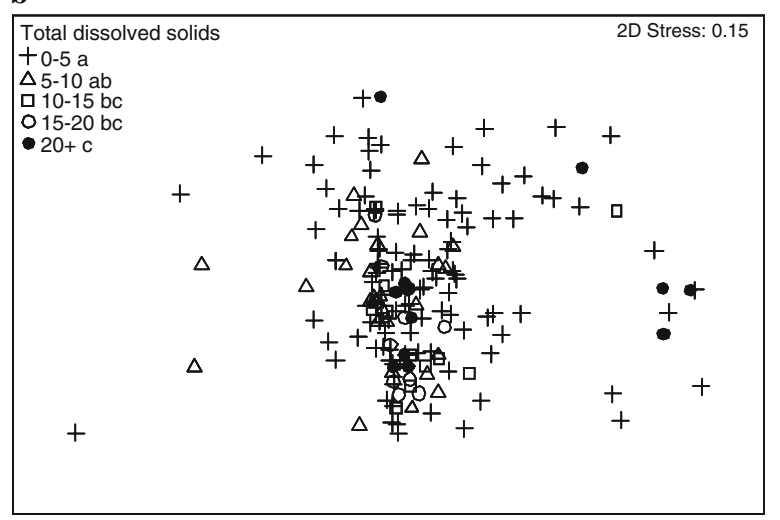

Fig. 3 NMDS ordinations of (a) mesocosm and (b) field insect assemblages between salinity levels (gl ${ }^{-1} \mathrm{TDS}$. Post hoc comparisons (from PERMANOVA and NPMANOVA, respectively) of differences between salinity levels represented by a, b and c

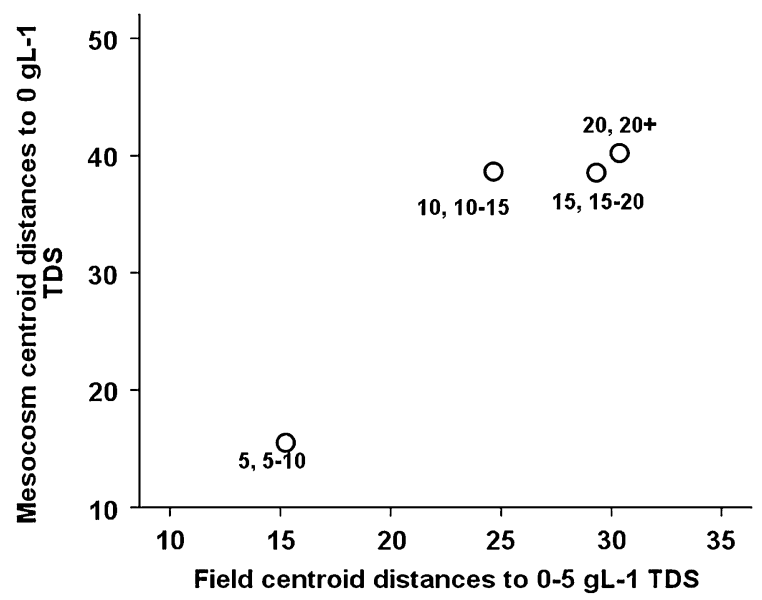

Fig. 4 The multivariate distance between the centroid of the lowest salinity level (mesocosm $0 \mathrm{gl}^{-1}$ TDS, field $0-5 \mathrm{gl}^{-1}$ TDS) and centroid of each increasing salinity level for mesocosm ( $y$-axis) and field ( $x$-axis) assemblages. Salinity level for each centroid distance labelled

population dynamics more widely (Spencer et al., 2002; James et al., 2003; Neilsen et al., 2003).

Influence of salinity on insects in mesocosms

The decline in total abundance, richness of taxa, ovipositing and colonising insects and change in assemblage structure of the mesocosms, as salinity increased, meet a priori expectations. As hypothesised, the mesocosm experiment demonstrated the most abundant taxa to colonise mesocosms (namely Cx. australicus, An. annulipes, C. alternans and
Paracymus sp.) are capable of selecting aquatic habitat based upon salinity.

Ovipositional preferences based on water body salinity occur widely in Culicidae (Trimble \& Wellington, 1979; Bailey et al., 1981; Pappas \& Pappas, 1983; Roberts, 1996). For example, Cx. quinquefasciatus preferentially oviposited in fresh water, rather than 10 or $23 \mathrm{gl}^{-1}$ TDS (Roberts, 1996). Culex australicus and An. annulipes are regarded at halophobic species (Liehne, 1991), and these species exhibited oviposition preferences in relation to salinity, in this study. It is possible these halophobic fauna occurred less frequently in saline mesocosms, due to egg or first instar mortality. However, empirical evidence demonstrates that mosquitoes preferentially oviposit in water that is suitable for egg and larval development (Blakeslee, 1952; Bailey et al., 1981; Pappas \& Pappas, 1983; Roberts, 1996). Additionally, observations that $C x$. australicus egg masses were frequent at low salinities and infrequent at high salinities suggest this is a true oviposition effect.

Oviposition by $C$. alternans was also influenced by salinity. Pinder et al. (2005) found that $C$. alternans occurs over a broad range of salinities (0-14 $\mathrm{gl}^{-1}$ TDS and possibly greater) in the field. In this study, C. alternans became rare as salinity increased in the mesocosms, and absent at $20 \mathrm{gl}^{-1}$ TDS. As such, our results suggest that $C$. alternans also preferentially oviposits in fresh water when available. In support of our results, Silberbush et al. (2005) observed a similar oviposition preference by Polypedilum nubiferum Skuse (Diptera: Chironomidae). 
Paracymus sp. colonised the mesocosms directly and was negatively related to increasing salinity. This relationship appears to be due to preferential selection for lower salinities. It is possible this salinity effect was due to mortality of Paracymus sp. at higher salinity levels. However, few carcases of Paracymus sp. were observed across all salinity levels (Carver, personal observation), suggesting that enhanced mortality is not a factor. It is unknown whether Paracymus sp. in the mesocosm constituted single or multiple species. Overall, our results from abundant taxa in the mesocosms support the hypothesis that salinity is a determinant of colonisation behaviour and the spatial distribution of organisms. Numerous other taxa occurred infrequently in the mesocosms. Beyond the salinities in which these taxa occurred, the relative influence of salinity on their colonisation is unknown.

Colonisation preferences by halophilic fauna are not clear in the mesocosms. For example, the culicid vector of Ross River virus (Alphavirus: Togoviridae), Ae. camptorhynchus, frequently occurs in the field and is found at greatest abundance in water bodies from 5 to $20 \mathrm{gl}^{-1}$ TDS (Carver, unpublished data), but does not readily oviposit in mesocosms. As such, it is difficult to conclude from the mesocosm data if halophilic fauna selectively colonise saline water bodies or are excluded from freshwater by competition or predation. It is possible that known halophiles, such as Necterosoma penicillatus Clark (Diptera: Dytiscidae) (Pinder et al. 2005), were less frequent in the mesocosms because this experiment was located in areas that were relatively unaffected by secondary salinisation. The occurrence of Necterosoma sp. at 15 and $20 \mathrm{gl}^{-1}$ TDS suggests these colonisations may be due to a halophile, such as $N$. penicillatus, and these taxa may have substantial dispersal abilities. However, the occurrence of Necterosoma penicillatus is not confirmed, as Necterosoma were not identified to species in this study. Further research is needed to confirm or refute halophilic colonisation preferences for $N$. penicillatus and other halophilic taxa.

As one would expect, the inhabitants of the mesocosms were insects capable of searching out habitat by flight. Diptera remained numerically more abundant than Coleoptera in mesocosm and field samples, most likely because their colonisation occurred by oviposition. In a similar experiment, Silberbush et al. (2005) also found Diptera to be the most abundant (>95\%) colonisers of mesocosm. In particular, Culicidae can lay large numbers of eggs (approximately 20-200) per female (Liehne, 1991). Consequently, insects resulting from oviposition must undergo development in that water body. Coleoptera, on the other hand, colonised the mesocosms as adults and it is possible they were temporary inhabitants, capable of entering, testing the suitability of a water body and departing if desired.

Ephemeral aquatic ecosystems are variable between sites in their size, dimensions, habitat and abiotic characteristics. In this study, it is not surprising that the effect of site is influential over individual and assemblages of insects or that some groups vary between sites and others do not. Kay et al. (2001) and Pinder et al. (2005) also found aquatic invertebrates in the study region were locally heterogeneous due to variation in habitat.

Salinity, colonisation behaviour and insects in the field

It was also hypothesised that colonisation responses to salinity in the mesocosms would reflect distributions of taxa in the field surveys. Culex australicus and An. annulipes had similar relationships to salinity in the mesocosm and field samples, suggesting that for these species salinity is a determinant of oviposition behaviour and distribution. However, in contrast to our hypotheses, the overall composition of taxa from the field did not consistently reflect observations in the mesocosms, suggesting colonisation behaviour based on salinity may not be a broad determinant of organism occurrence.

Disparities between experimental data and field distributions are not uncommon (Blakeslee, 1952; Sinha, 1976; Bailey et al. 1981; Williams et al. 1990). However, an acknowledged limitation of this study is Coleoptera and non-culicid Diptera were not identified to species. Potentially, this meant that successions of species may occur along the salinity gradient, which is not detected here. The abundance of Chironomidae, for example, is distinctly different between the field and mesocosms. This lack of resemblance between chironomid samples is probably due to the occurrence of multiple species in the field samples and wide salinity tolerances within this family (Bunn \& Davies, 1992), whereas chironomids were of a single species in the mesocosms. Thus, the 
results and their subsequent interpretation would most likely have benefited from species level identification of taxa. However, it should be noted that the average abundance of insects in the field exhibited a general decline at $20+\mathrm{gl}^{-1} \mathrm{TDS}$, bearing some similarity to the mesocosm results.

Dipteran families in the WA Wheatbelt occur within relatively wide salinity boundaries (Kay et al., 2001; Pinder et al., 2005). For example, Chironomidae, Ephydridae and Dolichopodidae are observed up to and exceeding salinities of $100 \mathrm{gl}^{-1}$ TDS (Kay et al., 2001; Pinder et al., 2005). However, Pinder et al. (2005) observed that few species exceed $10 \mathrm{gl}^{-1}$ TDS. With the exemption of Chironomidae, this study found a general decline in the abundance of Dipteran families, lumped together, in the field (GZLM $\chi^{2}=160.046$, df $\left.=4, P<0.001\right)$ and mesocosms $\quad\left(\right.$ GEE $\left.\chi^{2}=13.980, \quad \mathrm{df}=4, \quad P<0.01\right)$. Numerous taxa, such as Ephydridae, L. zealandicus and Necterosoma sp., were not abundant enough in both field and mesocosms for direct individual comparisons to be made.

Similar to the field samples in this study, Pinder et al. (2005) found that species richness of water bodies 3-20 $\mathrm{gl}^{-1}$ TDS was comparable to $3 \mathrm{gl}^{-1}$ TDS sites. However, Pinder et al. (2005) noted that variability (around the regression line) in observations contracted above $4.1 \mathrm{gl}^{-1}$ TDS, suggesting species structure became more uniform. In this study, a contraction in the variability of taxa richness was not observed at salinities $>5 \mathrm{gl}^{-1}$ TDS in the field, which may reflect the level of taxonomic discrimination used. In contrast, the richness of taxa in mesocosms was clearly related to salinity and may reflect general patterns in faunal preferences when a range of salinities are locally available, or that local colonising taxa are freshwater species. Many artificial fresh water habitats remain ubiquitous across inland southwest WA in the form of farm dams, with $50-72 \%$ of local aquatic fauna known to occur within them (Halse et al., 2003; Benier, 2005). In a similar way that the salinity of our mesocosms influenced colonisation by certain taxa and assemblage of insects, farm dams that occur in proximity to salinity affected water bodies, may provide refugia and influence the spatial distribution, population dynamics and persistence of halosensitive fauna across the WA landscape. Further research is needed to examine the importance of farm dams to aquatic fauna in saline areas.
Relationships have been found between salinity and Coleoptera over salinity ranges of $0-8 \mathrm{gl}^{-1}$ TDS in other studies (Lancaster \& Scudder, 1987). However, many Coleoptera in inland southwest WA appear to be relatively salt tolerant, and the same correlation was not found in this study (over $0-8$ or 0-20 $\mathrm{gl}^{-1} \mathrm{TDS}$ ) or in other studies in the same region (Kay et al., 2001; Bailey et al., 2002; Pinder et al., 2004, 2005). It is also possible that salinity differences in abundances of Coleoptera, between mesocosm and field samples, may partially be due to some field Coleoptera having developed from eggs within water bodies, whereas all Coleoptera colonised mesocosms as adults. However, if salinity is a determinant of colonisation for coleopteran taxa then it would be expected that oviposition preferences would also reflect colonisation behaviour.

Other biotic and abiotic variables (such as predation, competition, microhabitat structure and stochastic encounters with water bodies) may be more influential than salinity on our measures of organism occurrence (Williams et al., 1990; Kay et al., 2001), potentially explaining differences between mesocosm and field results. Ovipositing and colonising insects are known to choose habitat that maximises survival and fitness (Spencer et al., 2002; Blaustein et al., 2004). Bailey et al. (1981) suggested that favourable habitat may be more important than salinity to the oviposition behaviour of some insects. In addition, the field sampling in this study was undertaken over a more broad time scale than the mesocosm experiment. It is acknowledged that the abundance of many insects fluctuates over time. Consequently, the abundance of some taxa may fluctuate over the temporal sampling period in this study. However, it is considered unlikely that temporal fluctuations of abundance would affect the relative difference in preference between salinity levels, if salinity is a significant determinant of colonisation behaviour.

\section{Influence of salinity on insect assemblages}

The influence of abiotic factors on colonisation behaviour may strongly influence assemblage structure and population dynamics (James et al., 2003; Silberbush et al., 2005). Analysis of assemblages revealed that salinity is a determinant of assemblages that colonise the mesocosms, broadly influencing 
selective behaviour. Assemblage structure of insects in the field also changed along the salinity gradient, which is consistent with other studies (Cale et al., 2004; Halse et al., 2004). However, our taxonomic investigations demonstrate abundance of individual taxa between salinity levels in the mesocosms is relatively dissimilar from abundance of individual taxa between salinity levels in the field. Clearly this study (and other examples, such as Sinha, 1976) demonstrates that experimental results, of how salinity influences colonisation behaviour, are not always consistent, at least statistically, with observations from the field (Blakeslee, 1952; Sinha, 1976; Trimble \& Wellington, 1979; Bailey et al., 1981; Pappas \& Pappas, 1983).

Using patterns of multiple taxa undoubtedly incorporates indirect effects that may not be related to salinity, such as cascading effects species have upon the occurrence of each other, through bottom-up or top-down controls. However, the use of multiple taxa provides a more holistic picture of the salinity relationship on insect assemblages. While the assemblage structure of insects was relatively dissimilar between mesocosm and field samples, and colonisation behaviour was not a clear determinant of taxonomic occurrence in the field, both exhibited a similar gradient of change in multivariate space associated with salinity. This suggested that salinity is, broadly, a useful mechanism to examine how abiotic factors influence the distribution of assemblages as a whole (Cale et al., 2004; Halse et al., 2004; Piscart et al., 2005b; Silberbush et al., 2005).

Conclusions and environmental and management implications

Understanding mechanisms that generate the spatial distribution of species is a central theme in ecology and crucial to the conservation and restoration of threatened species. Approximately one-third of aquatic invertebrate diversity in the inland southwest of Western Australia is predicted to disappear with the expansion of anthropogenic exacerbated land salinisation (Halse et al., 2003). Yet, little consideration has been given to the role of behaviour in colonisation, or the availability of anthropogenic-created freshwater habitats. Findings here give empirical support to the importance of behavioural ecology in the spatial distribution of aquatic invertebrates and their assemblages across a landscape affected by salinity (Spencer et al., 2002; Silberbush et al., 2005). In particular, behaviour appears to be a determinant of $C x$. australicus and An. annulipies distributions in the field. However, our interpretations to other taxa in the field are restricted, probably due to the level of taxonomic discrimination used. As such, results here may be conservative of the importance of behaviour to generating spatial distribution. Colonisation behaviour is an important consideration for ecosystem management and restoration.

Acknowledgements This study was supported by Land and Water Australia, through a Science and Innovation Award from the Australian Government Bureau of Rural Sciences. This study was also supported by the Australian and Jean Rogerson Postgraduate awards. The Department of Environment and Conservation granted authority to enter land (CE001070) and provided licenses to collect aquatic fauna (SF005093). The authors would like to acknowledge the contribution of several volunteers that helped with all aspects of the fieldwork. Two anonymous reviewers provided comments that greatly improved this paper.

\section{References}

Anderson, M. J., 2004. NPMANOVA: A FORTRAN Computer Program for Non-Parametric Permutational Multivariate Analysis of Variance. Department of Statistics. University of Auckland, Auckland, New Zealand.

Anderson, M. J., 2005. PERMANOVA: A FORTRAN Computer Program for Permutational Multivariate Analysis of Variance. Department of Statistics. University of Auckland, Auckland, New Zealand.

Bailey, P., P. Boon \& K. Morris, 2002. Australian Biodiversity: Salt Sensitivity Database. Monash University and Victorian University of Technology.

Bailey, D. L., P. E. Kaiser, D. A. Focks \& R. E. Lowe, 1981. Effects of salinity on Anopheles albimanus: ovipositional behavior, immature development and population dynamics. Mosquito News 41: 161-167.

Benier, J.-M., 2005. The Role of Farm Dams as Refugia for Aquatic Invertebrates in a Salinised Landscape, South Western Australia. Centre for Ecosystem Management. Unpublished MSc thesis. Edith Cowan University, Western Australia, Australia.

Blakeslee, D. L., 1952. Chloride ion tolerance of four mosquitoes of Okinawa. Mosquito News 12: 191-194.

Blasius, B. J. \& R. W. Merritt, 2002. Field and laboratory investigations on the effects of road salt $(\mathrm{NaCl})$ on stream macroinvertebrate communities. Environmental Pollution 120: 219-231.

Blaustein, L., M. Kiflawi, A. Eitam, M. Mangel \& J. E. Cohen, 2004. Oviposition habitat selection in response to risk of predation in temporary pools: mode of detection and 
consistency across experimental venue. Oecologia 138: 300-305.

Bunn, S. E. \& P. M. Davies, 1992. Community structure of the macroinvertebrate fauna and water quality of a saline river system in south-western Australia. Hydrobiologia 248: 143-160.

Cale, D. J., S. A. Halse \& C. D. Walker, 2004. Wetland monitoring in the wheatbelt of south-west Western Australia: site descriptions, waterbird, aquatic invertebrate and groundwater data. Conservation Science of Western Australia 5: 20-135.

Clark, T. M., B. J. Flis \& S. K. Remold, 2004. Differences in the effects of salinity on larval growth and developmental programs of a freshwater and a euryhaline mosquito species (Insecta: Diptera, Culicidae). Journal of Experimental Biology 207: 2289-2295.

Crain, C. M., B. R. Silliman, S. L. Bertness \& M. D. Bertness, 2004. Physical and biotic drivers of plant distribution across estuarine salinity gradients. Ecology 85: 25392549.

George, R., J. Clarke \& P. English, 2006. Modern and palaeogeographic trends in the salinisation of the Western Australian Wheatbelt. Proceedings of the Australian Earth Sciences Convention 2006, Melbourne. http://www.earth 2006.org.au/papers/extendedpdf/George\%20Richard\%20$\% 20$ Modern $\% 20$ and \%20palaeogeographic-extended.pdf [accessed September 22, 2006].

Hagman, M. \& R. Shine, 2006. Effects of invasive cane toads on Australian mosquitoes: does the dark cloud have a silver lining? Biological Invasions 9: 445-452.

Halse, S. A., 1981. Faunal assemblages of some saline lakes near marchagee Western Australia. Australian Journal of Marine \& Freshwater Research 32: 133-142.

Halse, S. A., M. N. Lyons, A. M. Pinder \& R. J. Shiel, 2004. Biodiversity patterns and their conservation in the wetlands of the Western Australia wheatbelt. Records of the Western Australian Museum. Supplement No. 67: 337-364.

Halse, S. A., J. K. Ruprecht \& A. M. Pinder, 2003. Salinisation and prospects for biodiversity in rivers and wetlands of south-west Western Australia. Australian Journal of Botany 51: 673-688. doi:10.1071/BT02113.

Hart, E. A. \& J. R. Lovvorn, 2005. Patterns of macroinvertebrate abundance in inland saline wetlands: a trophic analysis. Hydrobiologia 541: 45-54.

Hassell, K. L., B. J. Kefford \& D. Nugegoda, 2006. Sub-lethal and chronic salinity tolerances of three freshwater insects: Cloeon sp. and Centroptilum sp. (Ephemeroptera: Baetidae) and Chironomus sp. (Diptera: Chironomidae). Journal of Experimental Biology 209: 4024-4032.

James, K. R., B. Cant \& T. Ryan, 2003. Responses of freshwater biota to rising salinity levels and implications for saline water management: a review. Australian Journal of Botany 51: 703-713.

Jardine, A., P. Speldewinde, S. Carver \& P. Weinstein, 2007. Dryland salinity and ecosystem distress syndrome: human health implications. EcoHealth 4: 10-17.

Jeffery, J. A. L., B. H. Kay \& P. A. Ryan, 2005. Development time and survival of Verrallina funerea (Theobald) (Diptera: Culicidae) immatures and other brackish water mosquito species in southeast Queensland, Australia. Australian Journal of Entomology 44: 226-232.
Juliano, S. A. \& M. E. Gravel, 2002. Predation and the evolution of prey behavior: an experiment with tree hole mosquitoes. Behavioral Ecology 13: 301-311.

Kay, W. R., S. A. Halse, M. D. Scanlon \& M. J. Smith, 2001. Distribution and environmental tolerances of aquatic macroinvertebrate families in the agricultural zone of southwestern Australia. Journal of the North American Benthological Society 20: 182-199.

Kefford, B. J., T. Paradise, P. J. Papas, E. Fields \& D. Nugegoda, 2003. Assessment of a system to predict the loss of aquatic biodiversity from changes in salinity. Report to Land and Water Australia, Project No: VCE 17, Perth, Western Australia.

Keighery, G. J., S. A. Halse, N. L. McKenzie \& M. S. Harvey (eds) 2004. A biodiversity survey of the Western Australian agricultural zone. Records of the Western Australian Museum. Supplement; no. 67. Western Australian Museum, Perth, Western Australia: 384pp.

Lancaster, J. \& G. G. E. Scudder, 1987. Aquatic Coleoptera and Hemiptera in some Canadian saline lakes: patterns in community structure. Canadian Journal of Zoology 65: 1383-1390.

Liehne, P. F. S., 1991. An Atlas of the Mosquitoes of Western Australia. Health Department of Western Australia, Perth.

Lindsay, M. D., A. Jardine, C. A. Johansen, A. E. Wright, S. A. Harrington \& P. Weinstein, 2007. Mosquito (Diptera: Culicidae) fauna in inland areas of south west Western Australia. Australian Journal of Entomology 46: 60-64.

Marshall, N. A. \& P. C. E. Bailey, 2004. Impact of secondary salinisation on freshwater ecosystems: effects of contrasting, experimental, short-term releases of saline wastewater on macroinvertebrates in a lowland stream. Marine and Freshwater Research 55: 509-523.

McKenzie, N. L., A. H. Burbidge \& J. K. Rolfe, 2003. Effect of salinity on small, ground-dwelling animals in the Western Australian wheatbelt. Australian Journal of Botany 51: 725-740.

Mokany, A. \& R. Shine, 2003. Oviposition site selection by mosquitoes is affected by cues from conspecific larvae and anuran tadpoles. Austral Ecology 28: 33-37.

Neilsen, D. L., M. Brock, G. Rees \& D. Baldwin, 2003. Effects of increasing salinity on freshwater ecosystems in Australia. Australian Journal of Botany 51: 655-665.

Pappas, L. G. \& C. D. Pappas, 1983. Laboratory studies on the significance of sodium chloride as an oviposition deterrent in Culiseta inornata. Mosquito News 43: 153-155.

Pinder, A. M., S. A. Halse, J. M. McRae \& R. J. Shiel, 2004. Aquatic invertebrate assemblages of wetlands and rivers in the wheatbelt region of Western Australia. Records of the Western Australian Museum. Supplement No. 67:7-37.

Pinder, A. M., S. A. Halse, J. M. McRae \& R. J. Shiel, 2005. Occurence of aquatic invertebrates of the wheatbelt region of Western Australia in relation to salinity. Hydrobiologia 543: 1-24.

Piscart, C., A. Lecerf, P. Usseglio-Polatera, J. C. Moreteau \& J. N. Beisel, 2005a. Biodiversity patterns along a salinity gradient: the case of net-spinning caddisflies. Biodiversity and Conservation 14: 2235-2249.

Piscart, C., J. C. Moreteau \& J. N. Beisel, 2005b. Biodiversity and structure of macroinvertebrate communities along a 
small permanent salinity gradient (Meurthe River, France). Hydrobiologia 551: 227-236.

Roberts, D., 1996. Mosquitoes (Diptera: Culicidae) breeding in brackish water: Female ovipositional preferences or larval survival? Journal of Medical Entomology 33: 525-530.

Roberts, D. M. \& R. J. Irving-Bell, 1997. Salinity and microhabitat preferences in mosquito larvae from southern Oman. Journal of Arid Environments 37: 497-504.

Silberbush, A., L. Blaustein \& Y. Margalith, 2005. Influence of salinity concentration on aquatic insect community structure: a mesocosm experiment in the Dead Sea Basin Region. Hydrobiologia 548: 1-10.

Singleton, G., 1989. Population dynamics of an outbreak of house mouse (Mus domesticus) in the Mallee wheatlands of Australia-hypothesis of plague formation. Journal of Zoology 219: 495-515.

Sinha, V. P., 1976. Further observations on the physiochemical factors of the breeding places of Culex quinquesfasciatus Say = fatigans Wied. Mosquito News 36: 358-360.

Spencer, M., L. Blaustein \& J. E. Cohen, 2002. Oviposition habitat selection by mosquitoes (Culiseta longiareolata) and consequences for population size. Ecology 83: 669-679.
Stav, G., L. Blaustein \& J. Margalith, 1999. Experimental evidence for predation risk sensitive oviposition by a mosquito, Culiseta longiareolata. Ecological Entomology 24: 202-207.

Stoks, R. \& M. A. McPeek, 2003. Antipredator behavior and physiology determine Lestes species turnover along the pond-permanence gradient. Ecology 84: 3327-3338.

Terpstra, J. W. \& A. D. Wilson, 1989. Grazing distribution of sheep and kangaroos in a semi-arid woodland. Applied Animal Behaviour Science 24: 343-352.

Trimble, R. M. \& W. G. Wellington, 1979. Effects of salinity on site selection by ovipositing Aedes togoi Diptera Culicidae. Canadian Journal of Zoology 57: 593-596.

Williams, D. D., 2003. The brackishwater hyporheic zone: invertebrate community structure across a novel ecotone. Hydrobiologia 510: 153-173.

Williams, W. D., A. J. Boulton \& R. G. Taaffe, 1990. Salinity as a determinant of salt lake Fauna-a question of scale. Hydrobiologia 197: 257-266.

Zalizniak, L., B. J. Kefford \& D. Nugegoda, 2006. Is all salinity the same? I The effect of ionic compositions on the salinity tolerance of five species of freshwater invertebrates. Marine and Freshwater Research 57: 75-82. 